\title{
Evaluation of predictive factors of vertebral compression fracture after conventional palliative radiotherapy for spinal metastasis from colorectal cancer
}

\author{
*Jeongshim Lee, MD,,2 Woo Joong Rhee, MD, Jee Suk Chang, MD, ${ }^{1}$ Sei Kyung Chang, MD, PhD, ${ }^{3}$ \\ and Woong Sub Koom, MD, PhD'
}

1Department of Radiation Oncology, Yonsei Cancer Center, Yonsei University College of Medicine, Seoul; ${ }^{2}$ Department of Radiation Oncology, Inha University Hospital, Incheon; and '3Department of Radiation Oncology, CHA Bundang Medical Center, CHA University, Seongnam, Republic of Korea

\begin{abstract}
OBJECTIVE Delayed consequences of spinal radiotherapy (RT), including vertebral compression fracture (VCF), are critical complications. However, the predisposing factors that contribute to VCF after conventional RT are unclear. The aim of this study was to assess the incidence of VCF and to determine the predictors of VCF following conventional spinal RT specific to colorectal cancer (CRC).

METHODS The authors retrospectively reviewed 237 spinal segments (147 metastatic and 90 nonmetastatic) in 53 patients with CRC who underwent RT with a median total dose of 30 Gy in 10 fractions between January 2007 and December 2014. The primary end point was the development of a VCF following RT, either de novo VCF or the progression of a baseline VCF. VCFs were assessed using the spinal instability neoplastic score (SINS) criteria.

RESULTS Among all 237 spinal segments, 22 VCFs (9.3\%) were observed following RT, including 13 de novo and 9 progressive fractures, and the median time to VCF was 4 months. All VCFs developed in metastatic spines. Among 147 metastatic spinal segments, 22 fractures were observed, with a 12-month cumulative incidence of VCF of $14.8 \%$. Results of multivariable analysis indicated sex $(p=0.023)$ and SINS class II/III $(p<0.001)$ as risk factors related to development of a VCF in metastatic spinal segments. Among the SINS criteria, a lytic tumor and the presence of a baseline VCF were identified as predictors of VCF in metastatic spinal segments.

CONCLUSIONS In osteolytic or mixed lesions that were predominant in spinal metastases of CRC, the incidence of VCF was not negligible, even in patients treated with conventional spinal RT. This was especially evident in patients with spinal metastases with a SINS score $\geq 7$. Presence of a baseline VCF after spinal RT is a predictor of VCF development and should be observed carefully.

https://thejns.org/doi/abs/10.3171/2017.6.SPINE17282
\end{abstract}

KEY WORDS spinal metastasis; radiotherapy; vertebral compression fracture; colorectal cancer; oncology

I $\mathrm{N}$ metastatic colorectal cancer (CRC), the bone, including the spine, is the third most common site for metastases following the liver and lungs. ${ }^{14,24}$ In addition, the incidence of bone metastases in patients with CRC is expected to increase because of the development of modern chemotherapy that leads to prolonged survival.,11,16, ${ }^{18,26}$ Spinal metastasis is a significant problem in metastatic disease, because it has nonfunctional consequences due to pain and leads to decreased quality of life as the result of neurological sequelae. ${ }^{25}$
Previous studies have demonstrated that radiotherapy (RT) is an efficacious treatment for spinal metastases in terms of palliation and the preservation of neurological function.5,6 After spinal RT, delayed consequences, including vertebral compression fracture (VCF), are critical complications in clinical practice. However, it is unknown which factors predispose patients to VCFs in association with spinal RT, especially for conventional RT, ${ }^{5}$ even though conventional RT is the most commonly used RT regimen for spinal metastasis in clinical practice. ${ }^{27}$

ABBREVIATIONS BED = biologically equivalent dose; $\mathrm{CRC}$ = colorectal cancer; $\mathrm{RT}$ = radiotherapy; SBRT = stereotactic body radiotherapy; SINS = spinal instability neoplastic score; VCF = vertebral compression fracture.

SUBMITTED March 7, 2017. ACCEPTED June 28, 2017.

INCLUDE WHEN CITING Published online December 22, 2017; DOI: 10.3171/2017.6.SPINE17282.

* Drs. S. K. Chang and W. S. Koom contributed equally to this work. 
Although several studies have assessed VCF after palliative RT, in particular stereotactic body radiotherapy (SBRT) or stereotactic radiosurgery, 1,12,15,21,22 there are limited data on the development of VCF after RT using conventional fractionation for spinal metastasis of CRC. In this study, we aimed to assess the incidence of VCF and to determine the predictors of VCF following conventional spinal RT for spinal metastasis of CRC.

\section{Methods \\ Study Design}

We retrospectively retrieved data from 53 patients with CRC with spinal metastasis who were treated with palliative RT between January 2007 and December 2014. There were a total of 237 spinal segments, consisting of 147 metastatic and 90 nonmetastatic segments. All patients were initially diagnosed with CRC based on pathological findings. They were clinico-radiologically diagnosed as having spinal metastasis of CRC based on MRI and/or CT findings and did not receive surgical treatment for spine metastasis. In addition, all patients had a follow-up period $>3$ months after spinal RT. Patients who were diagnosed as having osteoporosis and those who received hormone therapy and/or bisphosphonate therapy were excluded, because previous studies have reported that these factors might affect skeletal-related events, including pathologic fracture. ${ }^{4,13,20,23}$ We assessed the development of VCF after spinal RT in metastatic vertebral segments and nonmetastatic vertebral segments according to the RT volume. This study was approved by the institutional review board at Yonsei Cancer Center.

\section{RT Treatment}

All segments were treated with palliative RT using a conventional fraction size. The treatment volume of conventional RT for metastatic spine included the entire vertebral body of metastatic-involved spines, plus 1 or 2 vertebral nonmetastatic spine segments superior and inferior to the metastatic spinal segments. The RT modality, total dose, and fractions were determined with various schemes depending on the physician's judgment based on the patient's performance status, extent of spinal metastasis, and previous radiation.

\section{Pretreatment Assessment}

All irradiated spinal segments consisted of metastatic and nonmetastatic vertebrae and were examined in terms of the baseline vertebral status and clinical variables, such as age, sex, primary cancer, body mass index, spinal level, presence of pain, presence of metastasis, prior irradiation, and RT modality. Furthermore, each metastatic spinal segment was evaluated according to the baseline vertebral status and aforementioned clinical variables, and detailed radiological criteria for the spinal instability neoplastic score (SINS) were used to investigate significant factors predictive of VCF. The SINS is a scoring system of spinal instability based on 6 criteria consisting of location, intensity of pain, type of bone lesion, spinal alignment, vertebral body collapse, and posterolateral involvement, and it ranges from 0 to 18 points. ${ }^{8}$ The SINS divides the status of metastatic spinal segments into 3 categories according to score: class I, stable ( $0-6$ points); class II, potentially unstable (7-12 points); and class III, unstable (13-18 points). ${ }^{89}$ Pretreatment evaluation of patients' vertebral statuses was based on diagnostic MR and/or CT images with reference to RT and planning CT images. The type of bone lesion (blastic, lytic, or mixed) and spine alignment were classified by diagnostic and planning CT images. MR images were also used to evaluate paraspinal extension, vertebral body collapse, and posterior element involvement.

\section{Posttreatment Assessment}

A VCF was defined as the development of a new VCF or progressive VCF in a previously fractured vertebra after RT without evidence of tumor metastasis or progression. A progressive VCF was defined as $>20 \%$ reduction in vertebral body height, according to previous reports.,19 We assessed the development of VCFs using follow-up MR or CT images, which were usually obtained at 1-3 month intervals after RT or based on a physician's judgment for an image examination.

\section{Statistical Analysis}

The VCF rates by all categorical variables were compared using the Fisher exact test or chi-square test. The cumulative incidence of VCF was estimated from the end date of RT to the date that the VCF developed or the date of the last imaging study if there was no fracture, taking competing events such as deaths into consideration, and the differences were evaluated by Gray's test. ${ }^{10}$ Multivariable analysis was performed by comparing the cumulative incidence of VCF using Fine and Gray regression analysis. ${ }^{7}$ A p value $<0.05$ was considered statistically significant for all analyses. Statistical analyses were performed using R software version 3.2.2 (R Development Core Team).

\section{Results}

\section{Characteristics of Patients and Irradiated Spinal Segments}

The median age of the 53 patients was 61 years (range 35-77 years), and 26 (49\%) patients were men. The proportion of patients with adenocarcinoma (46 of 53,87\%) was larger than that of those with signet ring cell carcinoma (1 of 53,2\%) and neuroendocrine carcinoma (6 of 53, 11\%). Among all 237 irradiated spinal segments in 53 patients, the thoracic spine (102 of 237, 43.0\%) was the dominant site of spinal metastasis. One hundred forty-seven $(62.0 \%)$ vertebral segments had metastasis, 11 (4.6\%) received prior radiation, and $17(7.2 \%)$ had a preexisting baseline VCF.

Among all of the spinal segments, the median total dose, dose per fraction, and number of fractions of spinal RT were 30 Gy (range 8-60 Gy), 3 Gy (range 1.2-8 Gy), and 10 fractions (range 1-25 fractions), respectively. Thirty-one (13.1\%) segments were irradiated with a biologically equivalent dose (BED) $>39$ Gy for $\alpha / \beta=10$ $\left(\mathrm{BED}_{\alpha / \beta=10}\right)$. Among 147 metastatic spinal segments, $7.5 \%$ $(\mathrm{n}=11)$ had been previously irradiated, $41.4 \%(\mathrm{n}=61)$ 
TABLE 1. Baseline characteristics in all irradiated spinal and metastatic irradiated spinal segments

\begin{tabular}{|c|c|c|c|c|}
\hline \multirow[b]{2}{*}{ Variable } & \multicolumn{2}{|c|}{$\begin{array}{l}\text { All Irradiated } \\
\text { Segments }\end{array}$} & \multicolumn{2}{|c|}{$\begin{array}{c}\text { Metastatic Irradiated } \\
\text { Segments }\end{array}$} \\
\hline & No. & $\%$ & No. & $\%$ \\
\hline No. of segments & 237 & 100 & 147 & 100 \\
\hline \multicolumn{5}{|l|}{ Patient age, yrs } \\
\hline Median (range) & $61(35-77)$ & & $61(35-77)$ & \\
\hline$<60$ & 106 & 44.7 & 62 & 42.2 \\
\hline$\geq 60$ & 131 & 55.3 & 85 & 57.8 \\
\hline \multicolumn{5}{|l|}{ Sex } \\
\hline Male & 112 & 47.3 & 72 & 49.0 \\
\hline Female & 125 & 52.7 & 75 & 51.0 \\
\hline \multicolumn{5}{|l|}{ Primary site } \\
\hline Rectum & 136 & 57.4 & 85 & 57.8 \\
\hline Colon & 101 & 42.6 & 62 & 42.2 \\
\hline \multicolumn{5}{|l|}{ Pathology } \\
\hline Adenocarcinoma & 206 & 86.9 & 120 & 81.6 \\
\hline SRCa & 5 & 2.1 & 5 & 3.4 \\
\hline $\begin{array}{l}\text { Neuroendocrine } \\
\text { carcinoma }\end{array}$ & 26 & 11.0 & 22 & 15.0 \\
\hline \multicolumn{5}{|l|}{$\mathrm{BMI}, \mathrm{kg} / \mathrm{m}^{2}$} \\
\hline$<25$ & 185 & 78.1 & 120 & 81.6 \\
\hline$\geq 25$ & 52 & 21.9 & 27 & 18.4 \\
\hline \multicolumn{5}{|l|}{ Spinal level } \\
\hline Cervical & 33 & 13.9 & 22 & 15.0 \\
\hline Thoracic & 102 & 43.0 & 57 & 38.8 \\
\hline Lumbar & 77 & 32.5 & 50 & 34.0 \\
\hline Sacral & 25 & 10.5 & 18 & 12.2 \\
\hline \multicolumn{5}{|l|}{ Metastasis } \\
\hline Metastatic & 147 & 62.0 & & \\
\hline Nonmetastatic & 90 & 38.0 & & \\
\hline \multicolumn{5}{|l|}{ Prior irradiation } \\
\hline No & 226 & 95.4 & 136 & 92.5 \\
\hline Yes & 11 & 4.6 & 11 & 7.5 \\
\hline \multicolumn{5}{|l|}{ Baseline VCF } \\
\hline No & 220 & 92.8 & 130 & 88.4 \\
\hline Yes & 17 & 7.2 & 17 & 11.6 \\
\hline \multicolumn{5}{|l|}{ Total dose, Gy } \\
\hline Median (range) & $30(8-60)$ & & $30(8-60)$ & \\
\hline$\leq 30$ & 209 & 88.2 & 132 & 89.8 \\
\hline$>30$ & 28 & 11.8 & 15 & 10.2 \\
\hline $\begin{array}{l}\text { Median dose of frac- } \\
\text { tion, Gy (range) }\end{array}$ & $3(1.2-8)$ & & $3(1.2-8)$ & \\
\hline $\begin{array}{l}\text { Median no. of frac- } \\
\text { tions (range) }\end{array}$ & $10(1-25)$ & & $10(1-25)$ & \\
\hline \multicolumn{5}{|l|}{$\mathrm{BED}_{\alpha / \beta=10}, \mathrm{~Gy}$} \\
\hline Median (range) & 39 (14-74) & & $39(14-74)$ & \\
\hline$\leq 39$ & 206 & 86.9 & 131 & 89.1 \\
\hline$>39$ & 31 & 13.1 & 16 & 10.9 \\
\hline
\end{tabular}

$\mathrm{BMI}=$ body mass index; $\mathrm{SRCa}=$ signet ring cell carcinoma.

All values reported as number (\%) unless otherwise indicated.

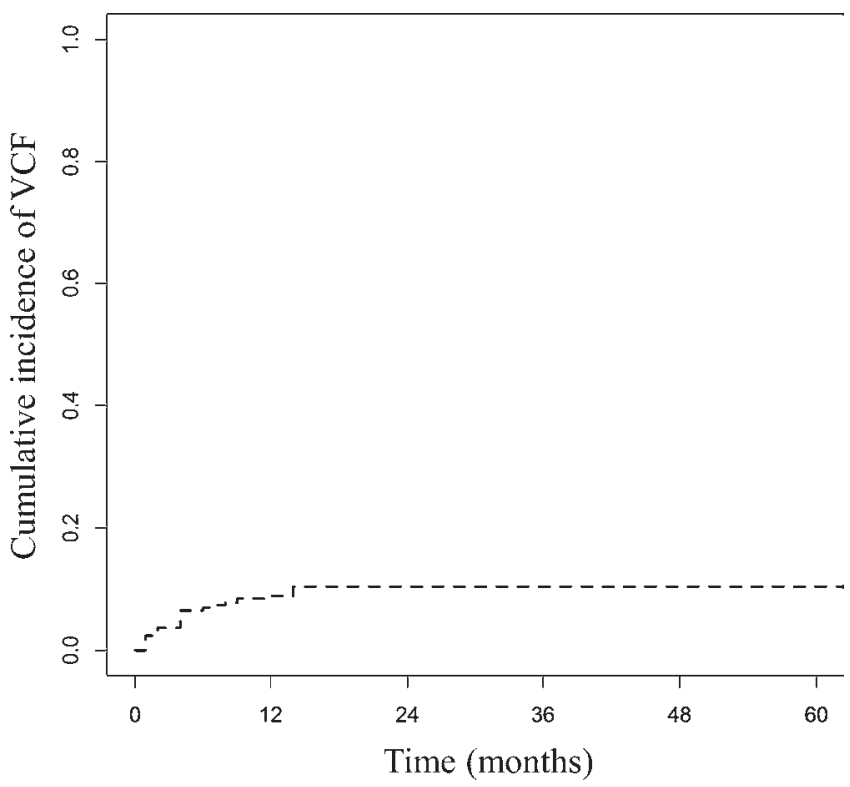

FIG. 1. Cumulative incidence of VCFs in all irradiated spinal segments (Gray's test).

had a lytic lesion, and $11.6 \%(\mathrm{n}=17)$ had a baseline VCF. Table 1 summarizes the baseline characteristics of all irradiated spinal segments and metastatic spine segments. In addition, the detailed dose scheme of spinal RT is shown in Supplementary Table 1.

\section{VCF Rate, Cumulative Incidence of VCF, and Predictive Variables for All Irradiated Spines}

The median duration of follow-up for all patients was 10 months (range 3-99 months). Among the 237 irradiated spinal segments, 22 VCFs (9.3\%) were observed following RT, including 13 de novo fractures and 9 progressive fractures, with a median time to development of 4 months (range 3-24 months). All VCFs developed in metastatic spines. Of 22 patients with a VCF, 9 underwent stabilization operation, and 13 remained asymptomatic without operation.

The VCF rate in all irradiated spines was significantly different according to metastatic involvement (metastatic vs nonmetastatic, $\mathrm{p}<0.001$ ) and presence of a baseline VCF (no vs yes, $\mathrm{p}<0.001$; Supplementary Table 2). The cumulative incidence of VCF at 12 months was $9.1 \%$ (Fig. 1). In the analysis of risk factors for the cumulative incidence of VCF, prior RT ( $\mathrm{p}=0.035)$, presence of a baseline VCF ( $p<0.001)$, and SINS class ( $p<0.001$ ) were significant factors (Supplementary Table 3 ).

Among irradiated nonmetastatic spine segments, only $1 \mathrm{VCF}$ developed in a 70-year-old woman. She developed a VCF 5 months after conventional palliative RT ( 25 Gy in 10 fractions). She underwent decompressive laminectomy for the VCF, and a metastatic tumor was detected on pathological examination. In this case, a VCF in an irradiated nonmetastatic spine may be induced by either progression of an adjacent involved metastatic spine segment or progression of an undetectable existing metastatic tumor. Finally, the cumulative incidence of VCF at 12 
TABLE 2. VCF rate according to components of SINS in 147 metastatic spinal segments

\begin{tabular}{|c|c|c|c|c|}
\hline Variable & $\begin{array}{l}\text { No. of } \\
\text { VCFs } \\
(-)\end{array}$ & $\begin{array}{l}\text { No. of } \\
\text { VCFs } \\
(+)\end{array}$ & $\begin{array}{l}\text { VCF Rate (\%) } \\
\text { According to } \\
\text { SINS Variable }\end{array}$ & $\begin{array}{c}\mathrm{p} \\
\text { Value }\end{array}$ \\
\hline \multicolumn{5}{|l|}{ SINS component } \\
\hline Location & & & & 0.390 \\
\hline Rigid (S2-5) & 11 & 0 & 0.0 & \\
\hline Semirigid (T3-10) & 23 & 3 & 11.5 & \\
\hline $\begin{array}{l}\text { Mobile spine (C3-6, } \\
\text { L2-4) }\end{array}$ & 39 & 6 & 13.3 & \\
\hline $\begin{array}{l}\text { Junctional (occiput-C2, } \\
\text { C7-T2, T11-L1, } \\
\text { L5-S1) }\end{array}$ & 52 & 13 & 20.0 & \\
\hline Pain & & & & 0.283 \\
\hline Pain free & 7 & 0 & 0.0 & \\
\hline $\begin{array}{l}\text { Occasional \& nonme- } \\
\text { chanical }\end{array}$ & 60 & 8 & 11.8 & \\
\hline Mechanical & 58 & 14 & 19.4 & \\
\hline Bone lesion type & & & & $<0.001$ \\
\hline Blastic & 0 & 0 & & \\
\hline Mixed & 84 & 2 & 2.3 & \\
\hline Lytic & 41 & 20 & 32.8 & \\
\hline Spine alignment & & & & 0.481 \\
\hline Normal & 122 & 21 & 14.7 & \\
\hline Kyphosis/scoliosis & 3 & 1 & 25.0 & \\
\hline Subluxation/translation & 0 & 0 & & \\
\hline Vertebral body collapse & & & & $<0.001$ \\
\hline None of the below & 87 & 1 & 1.1 & \\
\hline $\begin{array}{l}\text { No collapse but }>50 \% \\
\text { of body involved by } \\
\text { tumor }\end{array}$ & 30 & 13 & 30.2 & \\
\hline$<50 \%$ & 6 & 7 & 53.8 & \\
\hline$\geq 50 \%$ & 2 & 1 & 33.3 & \\
\hline Posterolateral involvement & & & & 0.221 \\
\hline Not involved & 102 & 13 & 11.3 & \\
\hline Unilateral & 13 & 7 & 35.0 & \\
\hline Bilateral & 10 & 2 & 16.7 & \\
\hline SINS class & & & & $<0.001$ \\
\hline I & 83 & 1 & 1.2 & \\
\hline II & 42 & 20 & 32.3 & \\
\hline III & 0 & 1 & 100.0 & \\
\hline
\end{tabular}

$C=$ cervical; $L=$ lumbar $; S=$ sacral; $T=$ thoracic.

months related to conventional RT in nonmetastatic segments was $0 \%$.

\section{VCF Rate, Cumulative Incidence of VCF, and Predictive Variables in Metastatic Spines}

We observed 22 VCFs among 147 metastatic spinal segments (14.9\%) following RT, consisting of 13 de novo fractures and 9 progressive fractures in metastatic spines. Among the 147 metastatic spinal segments, the propor-
TABLE 3. VCF rate according to various factors in 147 metastatic spinal segments

\begin{tabular}{|c|c|c|c|c|}
\hline Variable & $\begin{array}{c}\text { No. of } \\
\text { VCFs (-) }\end{array}$ & $\begin{array}{c}\text { No. of } \\
\text { VCFs (+) }\end{array}$ & $\begin{array}{c}\text { VCF Rate (\%) } \\
\text { According to } \\
\text { Variables }\end{array}$ & $\begin{array}{c}p \\
\text { Value }\end{array}$ \\
\hline Age, yrs & & & & 0.102 \\
\hline$<60$ & 49 & 13 & 21.0 & \\
\hline$\geq 60$ & 76 & 9 & 10.6 & \\
\hline Sex & & & & 0.106 \\
\hline Male & 65 & 7 & 9.7 & \\
\hline Female & 60 & 15 & 20.0 & \\
\hline Primary site & & & & 0.816 \\
\hline Rectum & 73 & 12 & 14.1 & \\
\hline Colon & 52 & 10 & 16.1 & \\
\hline BMI, $\mathrm{kg} / \mathrm{m}^{2}$ & & & & 0.243 \\
\hline$<25$ & 104 & 16 & 13.3 & \\
\hline$\geq 25$ & 21 & 6 & 22.2 & \\
\hline Prior irradiation & & & & 0.215 \\
\hline No & 117 & 19 & 14.0 & \\
\hline Yes & 8 & 3 & 27.3 & \\
\hline $\mathrm{BED}_{\alpha / \beta=10}, \mathrm{~Gy}$ & & & & 0.017 \\
\hline$\leq 39$ & 115 & 16 & 12.2 & \\
\hline$>39$ & 10 & 6 & 37.5 & \\
\hline SINS class & & & & $<0.001$ \\
\hline I & 83 & 1 & 1.2 & \\
\hline$\|/ /\| I$ & 42 & 21 & 33.3 & \\
\hline
\end{tabular}

tions of SINS classes I, II, and III were $57.1 \%(\mathrm{n}=84)$, $42.2 \%(n=62)$, and $0.7 \%(n=1)$, respectively. Among the 6 SINS criteria, the type of bone lesion $(\mathrm{p}<0.001)$ and vertebral body collapse status $(p<0.001)$ were confirmed as risk factors related to the development of $\mathrm{VCF}$, whereas the location of the lesion $(p=0.390)$, intensity of the pain $(p=0.283)$, spinal alignment $(p=0.481)$, and posterolateral involvement $(\mathrm{p}=0.221)$ were not indicated as risk factors (Table 2). In particular, when examined by location of metastatic spinal segments, the VCF rate did not statistically significantly differ between junctional and nonjunctional spinal segments (20.0\% vs $10.9 \%$; $p=0.163)$. Furthermore, the VCF rate in metastatic spines was affected by the RT dose $(\leq 39$ vs $>39$ Gy of BED; $p=0.017)$ and SINS class (II/III vs I; $p<0.001$; Table 3 ).

Among all metastatic spines, the 12-month cumulative incidence of VCF was $14.8 \%$ (Fig. 2A). The cumulative incidence of VCF at 12 months with a SINS class I versus II/III was $0 \%$ versus $46.8 \%$ ( $<<0.001$ ) (Table 2, Fig. 2B). Results of multivariable analysis showed that the cumulative incidence of VCF in metastatic spine segments was significantly different according to the SINS class (II/III vs I, HR 36.02, 95\% CI 5.10-254.33; p < 0.001) and sex (female vs male, HR 2.73, 95\% CI 1.14-6.52; $\mathrm{p}=0.023$; Table 4). Figure 3 shows a representative metastatic spinal segment with a high SINS score that developed a VCF after conventional RT.

In terms of SINS radiographic and clinical compo- 

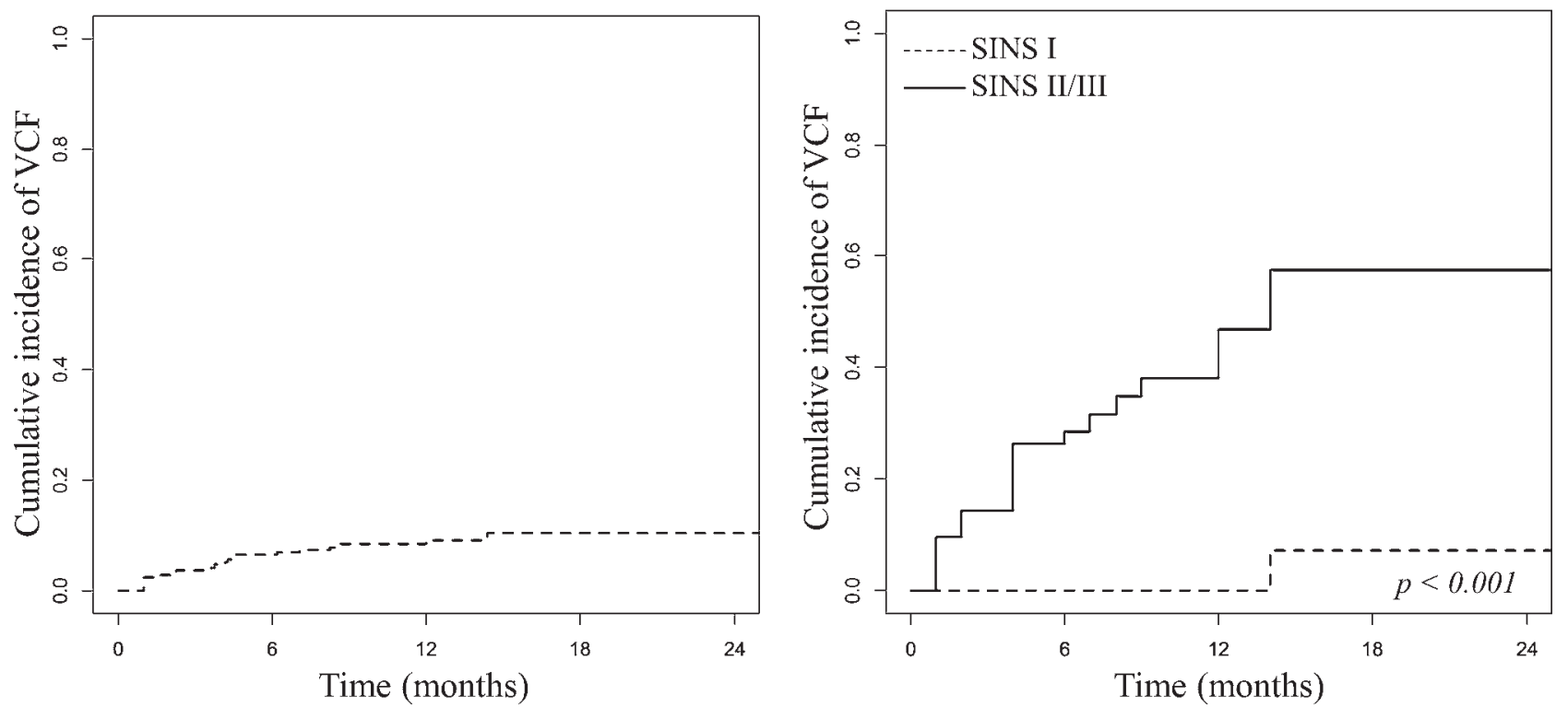

FIG. 2. Left: Cumulative incidence of VCFs in irradiated metastatic spinal segments. Right: Cumulative incidence stratified by the SINS class of irradiated metastatic spinal segments (Gray's test).

nents, we calculated the VCF rate in metastatic spines according to the observed risk factors, including the SINS class (I vs II/III), presence of a baseline VCF (no vs yes), and prior RT (no vs yes). The VCF rates for metastatic spines with a SINS class I and II/III were $1 \%$ and $33 \%$, respectively. Metastatic spines with a SINS class II/III with a lytic lesion had a $40 \%$ VCF rate, whereas those with a mixed lesion had a $13 \%$ VCF rate. Moreover, the VCF rate in metastatic spines with a SINS class II/III with a lytic lesion was $47 \%$ when a baseline VCF was present, whereas the incidence was 35\% when a baseline VCF was not present. In addition, metastatic spines with a SINS class II/III with a mixed lesion developed VCF at a rate of $50 \%$ when a baseline VCF was present, whereas the VCF rate was $8 \%$ when a baseline VCF was not present (Fig. 4).

During follow-up, local progression was observed in 37 of 147 metastatic spinal segments after conventional RT. The 6- and 12-month local control rates were $86.8 \%$ and $63.5 \%$, respectively. Among the 37 segments with local progression, the median time to local progression was 8 months (range $2-15$ months).

\section{Discussion}

In this study, we examined the incidence of VCF after conventional RT for spinal metastases. We presented the predictive factors of VCF precipitated by spinal metastasis of CRC after conventional palliative RT. These data highlight potential dangers associated with VCF and a spinal metastatic tumor with a high SINS score, particularly among patients with lesions with lytic features and/or a preexisting baseline VCF.

The cumulative incidence of VCF in patients with metastatic colorectal spine lesions without hormone or bisphosphonate therapy was $14.8 \%$ after palliative RT using the conventional scheme (most commonly 30 Gy in 10 fractions). In a previous systematic review, the prevalence of VCF after conventional RT was $<5 \% .{ }^{5}$ However, we noted a relatively high rate of post-RT VCF in our patients, suggesting that spinal metastatic features of CRC may contribute to an increased incidence of VCF.19,21,23

An Italian group reported that in skeletal metastases of CRC, both lytic lesions and mixed lytic/blastic lesions were more prevalent than true osteoblastic lesions. ${ }^{23}$ They also reported that the time to skeletal-related events (defined as a pathological fracture, the need for RT or operation of the bone, and spinal cord compression) was significantly shorter for patients with lytic lesions..$^{23}$ Furthermore, a study by the MD Anderson Cancer Center reported that spinal metastasis with a lytic feature was a significant risk factor for VCF after SBRT. ${ }^{3}$

In the current study, half of the patients had spinal metastasis with a lytic feature, and the remaining patients had spinal metastasis with a mixed lytic/blastic feature; no patients had spinal metastasis with a purely blastic feature. Thus, the incidence of VCF after spinal RT in this study was higher than that in cohorts with a heterogeneous mixture of spinal metastasis of various primary tumors in other studies. ${ }^{5,21}$ In our previous study examining small cohorts, we also found that the rate of VCF was 9\% after conventional radiation in metastatic spines with lytic or mixed lesions of CRC. ${ }^{17}$

We also examined the parameters associated with patients at risk for VCF. The effect of VCF after SBRT/stereotactic radiosurgery for spinal metastases has been well established in recent studies, and the incidence of VCF is estimated to be $11 \%-39 \% .1,12,15,21,22$ However, the relationship between VCF rate and clinical risk factors after conventional RT has not been fully investigated, because reports of spinal RT with conventional fractionation have generally focused on acute toxicities. ${ }^{5}$ We selected many risk factors, such as sex, age, body mass index, spinal level, metastasis, prior RT, presence of a baseline VCF, RT dose of BED, and SINS criteria, which enabled us to predict 
TABLE 4. Univariable and multivariable analysis of incidence of VCF in 147 metastatic spinal segments

\begin{tabular}{|c|c|c|c|c|}
\hline \multirow[b]{2}{*}{ Variable } & \multicolumn{2}{|c|}{ Univariable Analysis } & \multicolumn{2}{|c|}{ Multivariable Analysis } \\
\hline & $\operatorname{HR}(95 \% \mathrm{Cl})$ & p Value & $\mathrm{HR}(95 \% \mathrm{Cl})$ & $p$ Value \\
\hline Age, yrs & & 0.160 & & 0.930 \\
\hline$<60$ & 1.00 (ref) & & 1.00 (ref) & \\
\hline$\geq 60$ & $0.55(0.24-1.27)$ & & $0.95(0.33-2.69)$ & \\
\hline Sex & & 0.064 & & 0.023 \\
\hline Male & 1.00 (ref) & & 1.00 (ref) & \\
\hline Female & $2.24(0.95-5.27)$ & & $2.73(1.14-6.52)$ & \\
\hline Primary site & & 0.730 & & 0.860 \\
\hline Rectum & 1.00 (ref) & & 1.00 (ref) & \\
\hline Colon & $1.16(0.51-2.63)$ & & $0.91(0.34-2.44)$ & \\
\hline $\mathrm{BMI}, \mathrm{kg} / \mathrm{m}^{2}$ & & 0.230 & & 0.330 \\
\hline$<25$ & 1.00 (ref) & & 1.00 (ref) & \\
\hline$\geq 25$ & $1.68(0.71-3.95)$ & & $1.73(0.57-5.21)$ & \\
\hline Prior irradiation & & 0.180 & & 0.500 \\
\hline No & 1.00 (ref) & & 1.00 (ref) & \\
\hline Yes & $2.13(0.70-6.44)$ & & $1.61(0.40-6.49)$ & \\
\hline $\mathrm{BED}_{\alpha / \beta=10}, \mathrm{~Gy}$ & & 0.150 & & 0.140 \\
\hline$\leq 39$ & 1.00 (ref) & & 1.00 (ref) & \\
\hline$>39$ & $2.31(0.73-7.29)$ & & $3.08(0.69-13.66)$ & \\
\hline SINS class & & $<0.001$ & & $<0.001$ \\
\hline I & 1.00 (ref) & & 1.00 (ref) & \\
\hline$\|/\| \|$ & $38.20(5.48-266.00)$ & & $36.02(5.10-254.33)$ & \\
\hline
\end{tabular}

the risk for VCF development. The findings of our study showed that, in irradiated segments, all VCFs were in metastatic spines, particularly in patients with a baseline VCF and/or prior RT. Among the metastatic spine segments, the risk of VCF was significantly increased in women with a SINS class II/III.

Among SINS radiographic and clinical components, both the type of bone lesion and baseline vertebral body collapse significantly contributed to the development of

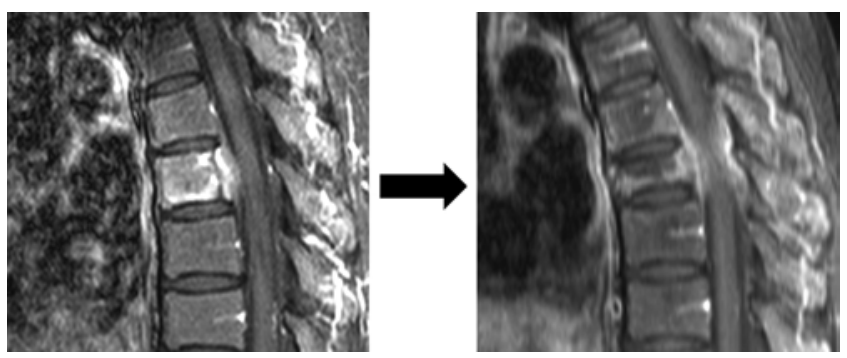

FIG. 3. MR image of a sagittal section before irradiation (left) and at development of a VCF (right). A metastatic spinal segment developed a de novo VCF in the T-7 vertebral segment 3 months after RT with 30 Gy in 10 fractions. Before RT, this metastatic vertebral segment had a high SINS score of 8 (semirigid location [1], mechanical pain [3], lytic lesion [2], normal spine alignment [0], no collapse but $>50 \%$ body involved by tumor [1], unilateral posterolateral element involvement [1]) without prior irradiation. Upper back pain and weakness in both legs were observed after VCF and were successfully treated by decompressive laminectomy. a VCF. Most patients with metastatic spines with a SINS class I did not develop a VCF, whereas patients with spinal metastatic segments with a SINS class II/III had a high rate of VCF. It was noted that patients with SINS class II/III metastatic segments with a baseline VCF developed VCF at an incidence of up to $50 \%$.

In addition, a preexisting baseline VCF was a strong risk factor for subsequent VCF, which has been reported in a recent, large multiinstitutional study and in a review article that evaluated VCF after spine SBRT., ${ }^{21,22}$ Our finding that presence of a baseline VCF was an independent predictor of fracture can be strongly associated with a spinal tumor due to CRC characterized by a lytic feature. Therefore, a spinal tumor with a baseline VCF must be monitored carefully in terms of the development of VCF after conventional palliative RT. Overall, we confirmed that SINS criteria are a powerful predictor associated with VCF in metastatic vertebral segments, even when using palliative RT with the conventional scheme as treatment.

Traditionally, conventional palliative RT includes all metastatic spine segments plus 1 or 2 levels of adjacent nonmetastatic spines superior and inferior to the metastatic spine. Although physicians are concerned about the risk of VCF in patients with irradiated nonmetastatic spines, we observed a VCF in an irradiated nonmetastatic spinal segment in only 1 patient. She was an elderly women with tumor progression, suggesting that the inclusion of adjacent nonmetastasis spine segments in conventional palliative RT is safe without any additional risk of VCF. However, further long-term follow-up should be performed to 


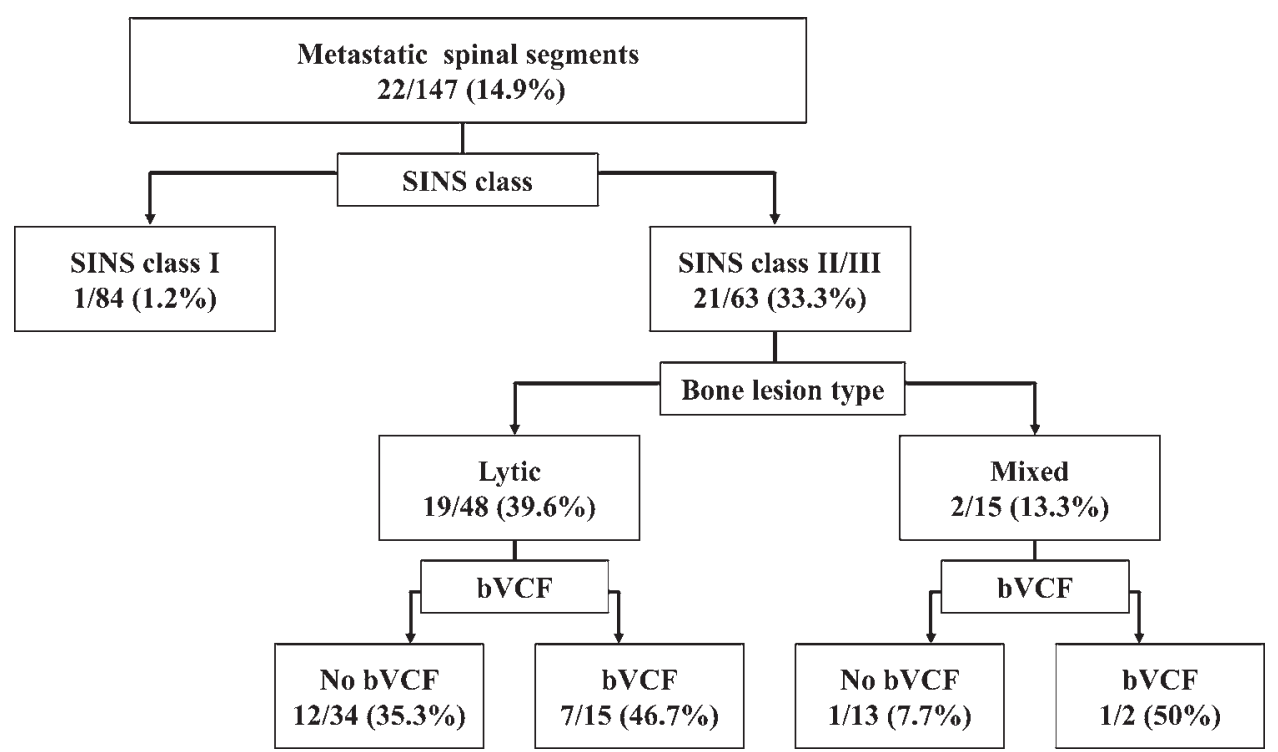

FIG. 4. Rate of VCFs in metastatic spinal segments according to the following criteria, in this order: SINS class, bone lesion type, and baseline VCF (bVCF).

confirm these findings, because the exact pathophysiology of a VCF related to conventional RT is not well defined. ${ }^{22}$

Our study has some limitations due to the retrospective data collection. First, limited clinical information was available; limited cohorts underwent spinal MRI at diagnosis and/or follow-up visit, even though MRI was more accurate in determining metastatic status or spine fracture than other imaging techniques. In addition, we could not rule out the confounding effect of the definite bone density that affected spine stability. Second, our study had a short-term follow-up period to assess delayed toxicity; thus, a longer follow-up may be needed to detect more cases of VCF.

\section{Conclusions}

In patients with metastatic colorectal spinal lesions, the incidence of VCF is not negligible due to the existence of osteolytic property, even when treating the spine with RT with conventional fractionation. In addition, in metastatic spine segments with regard to SINS components, the risk of VCF is significant in spinal segments with a lytic lesion and in those with a preexisting baseline VCF. Consideration of these factors associated with VCF is essential to appropriately assess toxicity after spinal RT.

\section{Acknowledgments}

This research was supported by a grant from the Korea Health Technology R\&D Project through the Korea Health Industry Development Institute funded by the Ministry of Health \& Welfare, Republic of Korea (HI16C0819).

\section{References}

1. Al-Omair A, Smith R, Kiehl TR, Lao L, Yu E, Massicotte EM, et al: Radiation-induced vertebral compression fracture following spine stereotactic radiosurgery: clinicopathological correlation. J Neurosurg Spine 18:430-435, 2013
2. Avallone A, Piccirillo MC, Aloj L, Nasti G, Delrio P, Izzo $\mathrm{F}$, et al: A randomized phase 3 study on the optimization of the combination of bevacizumab with FOLFOX/OXXEL in the treatment of patients with metastatic colorectal cancerOBELICS (Optimization of BEvacizumab scheduLIng within Chemotherapy Scheme). BMC Cancer 16:69, 2016

3. Boehling NS, Grosshans DR, Allen PK, McAleer MF, Burton AW, Azeem S, et al: Vertebral compression fracture risk after stereotactic body radiotherapy for spinal metastases. J Neurosurg Spine 16:379-386, 2012

4. Boonen S, Reginster JY, Kaufman JM, Lippuner K, Zanchetta J, Langdahl B, et al: Fracture risk and zoledronic acid therapy in men with osteoporosis. N Engl J Med 367:1714-1723, 2012

5. Chow E, Harris K, Fan G, Tsao M, Sze WM: Palliative radiotherapy trials for bone metastases: a systematic review. J Clin Oncol 25:1423-1436, 2007

6. Chow E, Zeng L, Salvo N, Dennis K, Tsao M, Lutz S: Update on the systematic review of palliative radiotherapy trials for bone metastases. Clin Oncol (R Coll Radiol) 24:112-124, 2012

7. Fine JP, Gray RJ: A proportional hazards model for the subdistribution of a competing risk. J Am Stat Assoc 94:496509, 1999

8. Fisher CG, DiPaola CP, Ryken TC, Bilsky MH, Shaffrey CI, Berven SH, et al: A novel classification system for spinal instability in neoplastic disease: an evidence-based approach and expert consensus from the Spine Oncology Study Group. Spine (Phila Pa 1976) 35:E1221-E1229, 2010

9. Fourney DR, Frangou EM, Ryken TC, Dipaola CP, Shaffrey CI, Berven SH, et al: Spinal instability neoplastic score: an analysis of reliability and validity from the spine oncology study group. J Clin Oncol 29:3072-3077, 2011

10. Gray RJ: A class of K-sample tests for comparing the cumulative incidence of a competing risk. Ann Stat 16:1141-1154, 1988

11. Hong YS, Nam BH, Kim KP, Kim JE, Park SJ, Park YS, et al: Oxaliplatin, fluorouracil, and leucovorin versus fluorouracil and leucovorin as adjuvant chemotherapy for locally advanced rectal cancer after preoperative chemoradiotherapy (ADORE): an open-label, multicentre, phase 2, randomised controlled trial. Lancet Oncol 15:1245-1253, 2014 
12. Jawad MS, Fahim DK, Gerszten PC, Flickinger JC, Sahgal A, Grills IS, et al: Vertebral compression fractures after stereotactic body radiation therapy: a large, multi-institutional, multinational evaluation. J Neurosurg Spine 24:928-936, 2016

13. Johnell O, Kanis JA: An estimate of the worldwide prevalence and disability associated with osteoporotic fractures. Osteoporos Int 17:1726-1733, 2006

14. Kanthan R, Loewy J, Kanthan SC: Skeletal metastases in colorectal carcinomas: a Saskatchewan profile. Dis Colon Rectum 42:1592-1597, 1999

15. Lam TC, Uno H, Krishnan M, Lutz S, Groff M, Cheney M, et al: Adverse outcomes after palliative radiation therapy for uncomplicated spine metastases: role of spinal instability and single-fraction radiation therapy. Int J Radiat Oncol Biol Phys 93:373-381, 2015

16. Landry JC, Feng Y, Prabhu RS, Cohen SJ, Staley CA, Whittington R, et al: Phase II trial of preoperative radiation with concurrent capecitabine, oxaliplatin, and bevacizumab followed by surgery and postoperative 5-fluorouracil, leucovorin, oxaliplatin (FOLFOX), and bevacizumab in patients with locally advanced rectal cancer: 5-year clinical outcomes ECOG-ACRIN Cancer Research Group E3204. Oncologist 20:615-616, 2015

17. Rhee WJ, Kim KH, Chang JS, Kim HJ, Choi S, Koom WS: Vertebral compression fractures after spine irradiation using conventional fractionation in patients with metastatic colorectal cancer. Radiat Oncol J 32:221-230, 2014

18. Rödel C, Graeven U, Fietkau R, Hohenberger W, Hothorn T, Arnold D, et al: Oxaliplatin added to fluorouracil-based preoperative chemoradiotherapy and postoperative chemotherapy of locally advanced rectal cancer (the German CAO/ARO/ AIO-04 study): final results of the multicentre, open-label, randomised, phase 3 trial. Lancet Oncol 16:979-989, 2015

19. Rose PS, Laufer I, Boland PJ, Hanover A, Bilsky MH, Yamada J, et al: Risk of fracture after single fraction image-guided intensity-modulated radiation therapy to spinal metastases. J Clin Oncol 27:5075-5079, 2009

20. Rosen LS, Gordon D, Tchekmedyian NS, Yanagihara R, Hirsh V, Krzakowski M, et al: Long-term efficacy and safety of zoledronic acid in the treatment of skeletal metastases in patients with nonsmall cell lung carcinoma and other solid tumors: a randomized, Phase III, double-blind, placebocontrolled trial. Cancer 100:2613-2621, 2004

21. Sahgal A, Atenafu EG, Chao S, Al-Omair A, Boehling N, Balagamwala EH, et al: Vertebral compression fracture after spine stereotactic body radiotherapy: a multi-institutional analysis with a focus on radiation dose and the spinal instability neoplastic score. J Clin Oncol 31:3426-3431, 2013

22. Sahgal A, Whyne CM, Ma L, Larson DA, Fehlings MG: Vertebral compression fracture after stereotactic body radiotherapy for spinal metastases. Lancet Oncol 14:e310-e320, 2013

23. Santini D, Tampellini M, Vincenzi B, Ibrahim T, Ortega C,
Virzi V, et al: Natural history of bone metastasis in colorectal cancer: final results of a large Italian bone metastases study. Ann Oncol 23:2072-2077, 2012

24. Schlüter K, Gassmann P, Enns A, Korb T, Hemping-Bovenkerk A, Hölzen J, et al: Organ-specific metastatic tumor cell adhesion and extravasation of colon carcinoma cells with different metastatic potential. Am J Pathol 169:1064-1073, 2006

25. Sutcliffe P, Connock M, Shyangdan D, Court R, Kandala NB, Clarke A: A systematic review of evidence on malignant spinal metastases: natural history and technologies for identifying patients at high risk of vertebral fracture and spinal cord compression. Health Technol Assess 17:1-274, 2013

26. Tournigand C, Chibaudel B, Samson B, Scheithauer W, Vernerey D, Mésange P, et al: Bevacizumab with or without erlotinib as maintenance therapy in patients with metastatic colorectal cancer (GERCOR DREAM; OPTIMOX3): a randomised, open-label, phase 3 trial. Lancet Oncol 16:14931505, 2015

27. Yu JI, Park HC, Ahn YC, Chung Y, Koom WS, Song SY: Variation in practice patterns of Korean radiation oncologists for spine metastasis between 2009 and 2014. Cancer Res Treat 48:1102-1109, 2016

\section{Disclosures}

The authors report no conflict of interest concerning the materials or methods used in this study or the findings specified in this paper.

\section{Author Contributions}

Conception and design: Koom, Lee, SK Chang. Acquisition of data: Lee, Rhee. Analysis and interpretation of data: Koom, Lee. Drafting the article: Lee, Rhee. Critically revising the article: Koom, Lee, SK Chang. Reviewed submitted version of manuscript: all authors. Approved the final version of the manuscript on behalf of all authors: Koom. Statistical analysis: Lee, JS Chang. Administrative/technical/material support: Koom, SK Chang. Study supervision: Koom, SK Chang.

\section{Supplemental Information Online-Only Content}

Supplemental material is available with the online version of the article.

Supplementary Tables 1-3. https://thejns.org/doi/suppl/10.317 1/2017.6.SPINE17282.

\section{Correspondence}

Woong Sub Koom, Department of Radiation Oncology, Yonsei University College of Medicine, 50-1 Yonsei-ro, Seodaemun-gu, Seoul 03722, Republic of Korea. email: mdgold@yuhs.ac. 